\title{
Beneficial Flat Grounding for Sprint Running by the Mechanism of Forward Leaning and Bending Knees
}

\author{
Hiroshi Bando ${ }^{1,2 *}$, Mitsuru Murakami ${ }^{3}$ and Akito Moriyasu ${ }^{4,5}$ \\ ${ }^{1}$ Tokushima University/Medical Research, Tokushima, Japan \\ ${ }^{2} J a p a n$ Masters Athletics, Tokushima Division, Board, Tokushima, Japan \\ ${ }_{3}^{3} J a p a n$ Masters Athletics, Kagawa Division, Vice-President, Kagawa, Japan \\ ${ }^{4}$ Rehabilitation Research Group for Body and Heart in Shikoku, Kagawa, Japan \\ ${ }^{5}$ Akiboshi Bright Star Training Rehabilitation Center, Kagawa, Japan \\ *Corresponding Author: Hiroshi Bando, Tokushima University/Medical and \\ Japan Masters Athletics, Tokushima Division, Board, Tokushima, Japan.
}

\author{
Received: March 14, 2020 \\ Published: March 18, 2020 \\ (C) All rights are reserved by Hiroshi \\ Bando., et al.
}

\begin{abstract}
Authors have continued actual attendance of races, lectures and workshops as board members of Japan Masters Athletics (JMA). The important factors for short distance sprint include flexibility, forward leaning, two axis operation, flat grounding, and not to kick on sole hallux area (foot thumb ball) but push on the heel. For faster and safer method of sprint, the movement of knee and pelvis is important. Just after flat grounding, the knee is bent and then femur and pelvis are sliding down forward immediately. This mechanism brings an athlete sprinter less power/tension and increased stride frequency.
\end{abstract}

Keywords: Japan Masters Athletics (JMA); Forward Leaning; Two Axis Operation; Flat Grounding; Sole Hallux Area; Short Distance Sprint

In recent years, sports lovers have been increasing in many countries. Tokyo Olympic and Paralympic games will be held in the summer of 2020, representing the health and peace of the world [1]. There are many people who are not professional but enjoying as amateurs. One of the related associations would be World Masters Athletics (WMA) across the world [2], and authors have been the members of Japan Masters Athletics (JMA) [3].

As the active members of JMA, authors have participated several races regularly a year. The author Bando had the record of $100 \mathrm{~m}$ dash in Tokushima prefecture, and the author Murakami had the record of $200 \mathrm{~m}$ dash in Kagawa prefecture before. Thus, thanks to the presence of masters' athlete, we have continued healthy and stable daily life so far.

As the lecturers of JMA, authors have continued for years giving lectures and workshops concerning how to run fast and safe with- out injuries. The subjects include Maters' athletes, healthy people, elderly people, patients with various disorders, and so on. There are two important points. One is the flexibility, and another is relaxed running method [4].

Concerning the former, any athlete has to prepare flexibility exercise before sports performance, and maintain the flexibility of the body to develop the ability [4]. Authors have continued practice and research for improving flexibility for athletes. The recommended method would be pole exercise [5], which has several versions for the different situations [6]. We have reported clinical research for the efficacy of the pole exercise $[7,8]$. Furthermore, we investigated the flexibility of thoracic and lumbar vertebrae [9].

In contrast, the latter has some factors, in which authors have proposed the necessary tips for faster and safer running for athletes [10]. They include the following three factors: 
i. Forward leaning: When running, try to lean forward as possible. The head, chest, waist and thighs would be straight and inclined forward [10]. To make the most of the potential energy of the body's center of gravity, we can convert it to forward propulsion power [11].

ii. Two axis operation: The footprint of placing both feet on the ground is on two parallel lines. As to running, the center of gravity of the body is not always in the center. The location of the center of gravity sways side to side for each step [11]. When both i) and ii) are combined together, the center of gravity of the body is falling lower diagonally forward, leading to acceleration.

iii. Flat grounding: Landing should be done so that the entire sole of the foot touches the ground flat. A bad example is when an athlete lands from the toe or the heel. Instead of kicking with sole hallux area (foot thumb ball), try always pushing on the heel [12]. Consequently, an athlete does not have to maximize muscle power, but can take the advantage of reaction power from the ground and can convert it into forward propulsion $[12,13]$.

Combined both of these researches (flexibility and better running), we have come to present a project of starting practice in the short distance sprint. We have taught a young male candidate of Paralympic games Tokyo 2020 for $100 \mathrm{~m}$ dash. In this article, we describe a better method of sprint which leads to faster running with low possibility of injuries $[14,15]$.

The subject is 21-years old male para-athlete runner. When he was 15 years old, the sprint time for $100 \mathrm{~m}$ was 13.38 seconds. After the authors gave him coaching for 1.5 years, the time became 11.84 seconds. There were some recommended points to improve, including i), ii), iii) as mentioned above, iv) do not make maximum power at plantar region [16], v) try to reduce tension psychologically [17], vi) make the arms not to move intentionally but keep arms just attached to the trunk with relaxed manner.

His practice is shown in the photograph (Figure 1). The grounding is soft and flat, keeping lower posture and moving the center of gravity smoothly [13]. Then, the start dash seems to be good with enough acceleration.

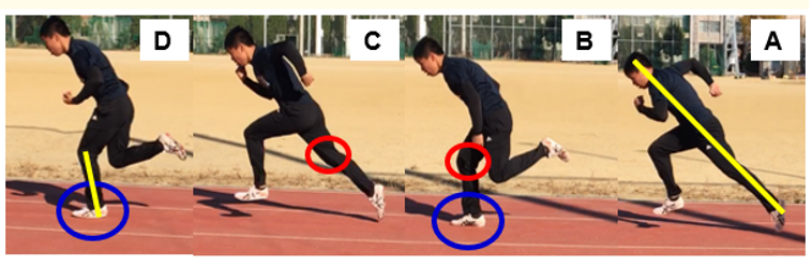

Figure 1: Typical flat grounding sprint with beneficial knee bending movement.

The photographs reveal $5,6,6.5$, and 7 steps after the start $(A, B$, C, D from the right):

A. In the $5^{\text {th }}$ step, a strong forward leaning is found in a straight line from the head to the foot, and the posture is good [11]. If only conscious of low posture, people tend to make just upper body bending, and often buttock left behind.

B. The $6^{\text {th }}$ step shows flat grounding on the entire sole of the right foot [13]. This is evaluated as a good landing posture. In this moment, it is good approach to have a consciousness of raising the toe upward [12]. Then, actually entire foot sole can land flat. If people have strength in the feet, they often kick in the toe [15].

C. At step 6.5, the benefits of flat grounding are clearly observed [13]. The right knee was bent immediately after scene B. Consequently, the center of gravity moved forward and downward, and the whole body was pushed forward without using forcing [9]. If people are kicking with the toes at scene B, the knee will not drop, but jump upwards, leading your entire body to float [15].

D. On $7^{\text {th }}$ step, left foot has successful flat grounding. It should be noted that the place where the left foot lands is slightly behind the left knee $[11,13]$. At the same time, the knee started to bend. Then, the body moves forward automatically without any braking with increased pitch. On the contrary, if the people place left foot just ahead of the left knee, they cannot proceed smoothly due to the influence of the braking [12]. A common bad running way is that people kick strongly with the toes, causing braking and decreased pitch [15]. 
Regarding the recommended method of sprint, a scheme of the movement of knee and pelvis is drawn in figure 2. Just after flat grounding, the knee is bent and then femur and pelvis are sliding down forward immediately. That is why an athlete can run faster with less power and increased pitch.

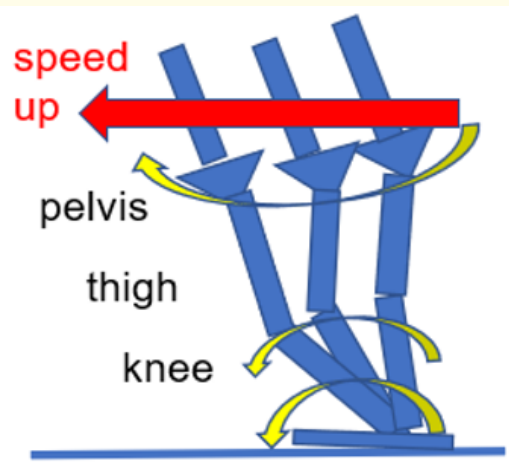

Figure 2: Scheme of the movement of knee and pelvis in good sprint.

Recent reports show some hints for excellent sprinters [18,19]. They include forward leaning, compact arm swing, lean turnover movement of the leg after kick $[11,15]$. These factors can contribute to raising the stride frequency and maintaining speed.

\section{Conclusion}

In summary, our continuing experience and research are described. Flat grounding is crucial for faster sprint, and knee and pelvic movements are important points. This article will be expected to contribute further development of research in the future.

\section{Bibliography}

1. Tokyo (2020).

2. World Masters Athletics (WMA).

3. Japan Masters Athletics Federations.

4. Zhao Y. "Analysis on Special Training Methods of Track and Field Sprint". Advanced Computer Science Research 59 (2017): 426-430.

5. Moriyasu A., et al. "Pole Exercise Causes Body Changes in Physical Flexibility and Exercise Function". Journal of Novel Physiotherapies 8 (2018): 377.
6. Bando H., et al. "Efficacy of rigid-pole exercise training for spinal mobility". International Physical Medicine and Rehabilitation Journal 4.5 (2019): 226-228.

7. Kurihara R., et al. "The influence of Pole exercise on the range of motion of thoracic spine". Clinical Research in Orthopaedics 2.1 (2019): 1-5.

8. Moriyasu A., et al. "Pole Exercise on Thorax Cage and its Influence on the Flexibility in Low Back-pain Patients". Journal of Novel Physiotherapies 9 (2019): 418.

9. Murakami M and Bando H. "Half foot training footwear for safer and faster running fromMasters Athletes to professional athletes". Neurophysiol and Rehab 2 (2019): 24-25.

10. Bando $\mathrm{H}$ and Murakami M. "The Function of Sole for Movement with Anterior Transverse Arch (ATA)". Acta Scientific Orthopaedics 2.3 (2019): 15-17.

11. Murakami M and Bando H. "Forward Leaning and Two Axis Operation for Effective and Safe Running". Sports Medicine and Rehabilitation Journal 3.4 (2018): 1042.

12. Bando H and Murakami M. "Arches and Points in the Foot of Running Athletes". Journal of Novel Physiotherapies 9 (2019): 405.

13. Murakami M and Bando H. "Flat Grounding by Consciousness of Plantar Triangle with Decreased Impact". Journal of Physical Medicine and Rehabilitation 1 (2018): 1-3.

14. ATEŞ B. "Age-related Effects of Speed and Power on Agility Performance of Young Soccer Players". Journal of Education and Learning 7.6 (2018): 93-99.

15. Murakami M and Bando H. "Smooth Running Without Power on Sole Hallucal Area". Research and Investigations in Sports Medicine 3.5 (2018).

16. Hayant S and Prashant U. "Effect of flat foot on the running ability of an athlete". Indian Journal of Orthopaedics Surgery 2.1 (2016): 119-123.

17. Selmi W., et al. "Self-confidence and affect responses to shortterm sprint interval training". Physiology and Behavior 188 (2018): 42-47.

18. Eke CU. "Agility quantification using body worn inertial sensors. Massachusetts Institute of Technology. Mater of Science in Mechanical Engineering". Graduate Program Committee (2017): 1-82. 
19. Mintah JK and Veney A. "Factors that differentiate successful and less successful sprinters". International Journal of Physical Education, Sports and Health 5.2 (2018): 330-334.

\section{Assets from publication with us}

- Prompt Acknowledgement after receiving the article

- Thorough Double blinded peer review

- Rapid Publication

- Issue of Publication Certificate

- High visibility of your Published work

Website: www.actascientific.com/

Submit Article: www.actascientific.com/submission.php

Email us: editor@actascientific.com

Contact us: +919182824667 